\title{
Pavlovian Craving and Overeating: A Conditioned Incentive Model
}

\author{
Remco C. Havermans
}

Published online: 16 February 2013

(C) Springer Science+Business Media New York 2013

\begin{abstract}
Food craving is an intense desire or urge to eat a certain food. It is under control of food-related cues, such as the sight, smell, and taste of one's favorite food items. It is argued that when the ingestion of food is associated with a rewarding consequence then the incentive value of that particular food increases and its sensory attributes become signals for satisfaction. This attribution of incentive value is the result of Pavlovian conditioning and is what makes certain food cues so desirable. Further, food craving reactivity reflects a central motivational state. It is suggested that cue exposure with response prevention may be a useful addition to weight loss treatment programs as it can teach one to handle strong urges to eat. Reducing exposure to food cues by regulating food marketing could further lower the number of occasions that food cravings are triggered.
\end{abstract}

Keywords Addiction · Cue exposure · Craving · Eating · Food cues $\cdot$ Urge to eat $\cdot$ Overeating

\section{Introduction}

In 1904, Ivan Petrovich Pavlov was awarded the Nobel Prize for Physiology and Medicine. He was given the Nobel Prize in recognition of his contribution to understanding the workings of the digestive system. In his Nobel lecture [1], some weeks before the award ceremony, Pavlov stressed how much the digestive system seems to be affected by appetite, or food cravings. If he and his research associates placed bread directly into the stomach of a subject

R. C. Havermans $(\bowtie)$

Faculty of Psychology and Neuroscience, Clinical Psychological

Science, Maastricht University, PO Box 616,

6200 MD Maastricht, the Netherlands

e-mail: r.havermans@maastrichtuniversity.nl (usually a dog), the bread took much longer to digest than when the subject had had the opportunity to eat the bread. The sight, smell, and taste of food stimulate appetite, inducing salivation and the flow of gastric juices, a "psychical" phenomenon aiding digestion. These findings are what inspired Pavlov's seminal work on classical conditioning, the learning of an association between a neutral conditioned stimulus (CS) and a biologically relevant unconditioned stimulus (UCS).

Examining classical conditioning, Pavlov [2] would typically feed a subject powdered meat, a UCS that (at least in Pavlov's stray dog subjects) elicits an unconditioned reflex (UR), namely salivation. When presentation of the UCS was always preceded by a CS (e.g., the ticking sound of a metronome), this particular CS gradually came to elicit a salivary reflex as well. The latter reflex is said to be a conditioned response (CR). The CR is conditional on the CS being associated with the UCS.

In his Nobel lecture, Pavlov remarked that "It has long been known for sure that the sight of tasty food makes a hungry man's mouth water". That mouth-watering experience is what links appetite to digestion, but also to meal initiation and food choice. The body prepares for food intake and not just any food, but the specific food one is exposed to. This preparatory cephalic phase response is thought to have been acquired through experience; it is a classically conditioned response [3-5].

Food cues (e.g., the sight, smell and taste of a favorite food) not only elicit preparatory bodily responses, but also behavioral responses (e.g., food seeking; [6]), and subjective responses such as a strong urge or craving to consume the food [7]. Together these cue elicited responses are referred to as cue reactivity $[8,9 \bullet]$. Cue elicited food craving is important for understanding overeating as it correlates with food intake (see, e.g., 
$[5,10])$. Further, these food cravings primarily concern palatable energy dense foods [11] and cue induced increases in the desire to eat or food craving have been observed to occur even when sated $[12,13]$.

Cue reactivity can be viewed as the result of a learning history, specifically a classical (or Pavlovian) conditioning history. In the present article, it is argued that flavor preference learning explains what types of foods are likely to be craved. Foods that have a rewarding consequence are endowed with an incentive value. This conditioned transfer of incentive value is what makes these foods desirable. Note that this means that craving is not the subjective interpretation of preparatory cephalic phase responses, as some scholars have suggested (see, e.g., [4]), but a central motivational state.

\section{Acquired Tastes}

A newborn baby has few flavor preferences; that is, it likes sweet taste and dislikes bitterness. Although as a foetus it may already have had some experience with different flavors from its mother's diet through tasting the amniotic fluid [14], the neonate can still be considered a blank slate in terms of flavor and food preferences. There is no such thing as a natural born gourmand. One needs to discover and learn the many distinct food flavors, and it is this experiential learning that shapes the palate. Pavlovian conditioning plays an important role in the development of these flavor preferences [15].

Rats readily come to prefer a novel flavor (a CS) when it is paired with the already liked sweet taste of saccharin (the UCS) [16]. Similarly, pairing a flavor CS with energy repletion (UCS) by means of ingesting a high caloric density food induces a positive preference shift in rats (e.g., 17-19). Man too is susceptible to both such flavor-flavor and flavor-nutrient learning. Zellner and colleagues [20] found that students preferred specific flavors of tea when previously these flavors had been paired with the sweet taste of sugar. Similarly, in a study with toddlers, Havermans and Jansen [21] paired a vegetable drink (CS) with the sweet taste of glucose (the UCS) and another vegetable CS was left unpaired. The toddlers received a total of six sips of each CS. At test, they were exposed to a range of six different vegetable drinks, including the two CSs of the conditioning phase. All drinks were now offered unsweetened and the children had to taste, evaluate, and rank order the drinks from most liked to least liked. The children clearly displayed a positive shift in preference for the CS that had previously been paired with the sweet UCS. This conditioning effect was replicated in a recent randomized trial. It was found that vegetable liking and intake increased as the likely result of a conditioning history in which a vegetable had been paired with another preferred taste [22].

Children have also been found to come to like specific flavors when pairing these flavors with a relatively high energy density as the result of added carbohydrates or dietary fats [23-26]. Martin Yeomans and colleagues [27] showed that flavor-flavor and flavor-nutrient learning may have additive effects on the shaping of food preferences. In their study, participants were given a sorbet with a specific flavor to taste and evaluate. This was followed by a period in which a group of participants received the sorbet paired with sucrose (sweet and energy dense), or with aspartame (a non-caloric sweetener), or with maltodextrin (non-sweet carbohydrate). At test, these participants showed increased liking and intake of the sorbet relative to two control groups, but this proved only significant in the participants in which the sorbet had previously been paired with the sucrose. In other words, sucrose appears to be a more potent reinforcer of a food preference than isocaloric maltodextrin, or equally sweet aspartame and this is likely due to sugar being both sweet and energy dense.

In sum, flavor preferences are shaped by experience. The associated consequences of certain food experiences may reinforce a preference for that food. Particularly sweet taste and energy repletion seem to serve that purpose well and may significantly strengthen one's food preference with just a few tastings (see [28]). The increased preference for a food is due to its ingestion being paired with a rewarding consequence. This consequence then serves as a UCS and incentive value is attributed to the food. The sight, smell, taste, and mouth feel of that food becomes desirable in and of itself and subsequent exposure to these sensory cues motivates its ingestion. That motivation is experienced and expressed as food craving. This explains why typically palatable high calorie foods such as chocolate are the foods that elicit craving [11, 29].

\section{Sensory Signals for Reward and Cue Elicited Craving}

As argued above, Pavlovian conditioning adds to the incentive value of specific food cues; that is, a food becomes better liked and hence more desired when its flavor (the CS) becomes associated with a potent UCS (e.g., sweet taste and/or energy repletion). For example, to a chocophile the sight and smell of chocolate signals pleasure and enjoyment and hence elicits chocolate craving. According to this conditioned incentive view, craving is a central motivational state. As such, this conditioned incentive model is different from earlier conditioning models of food craving (see also [30]). 
Anita Jansen [4], in line with Woods [3], has argued that eating (and particularly overeating) disrupts internal homeostasis. Different homeostatic reflexes then act to regulate the homeostatic perturbation. With regular eating occasions, especially eating binges during which one eats large amounts of often high calorie palatable foods, the sight, smell, and taste of these foods signal intake and hence these food cues come to elicit conditioned compensatory responses; that is, bodily responses preparing for the impending disruption of internal homeostasis. As these responses are opposite to the actual effect of food ingestion, these compensatory conditioned responses are often experienced as aversive (see also [31]). According to this model then, cue elicited craving (for food or indeed for psychotropic substances - see Nolan 2013 this issue [32]) is the indirect subjective interpretation of psychophysiological conditioned compensatory responses. The chocophile, when confronted with a piece of chocolate, desires to end his conditioned aversive state by giving in to his chocolate craving.

The compensatory response model is interesting and explains how we 'tolerate' our food [3], but the empirical evidence for this particular view on both drug and food craving reactivity is weak. As craving is deemed to be the subjective interpretation of bodily cue reactivity one would expect variations in such reactivity to be strongly associated with variation in experienced food cravings. This does not seem to be the case (see, e.g., [10, 33]). Typical bodily responses when exposed to drug or food cues include autonomic vasoconstriction (or the absence of vasodilation), increased skin conductance level, and an increased heart rate [4]. These responses rather reflect a general arousal pattern in response to a personally relevant stimulus than a conditioned response preparing for either food or drug intake $[33,34]$.

\section{Neurophysiology of Food Craving}

Cue elicited food craving results from a Pavlovian conditioned incentive value attributed to food cues. The sensory characteristics of a favored food signal enjoyment, reward. Findings from various neuroimaging studies provide important empirical support for this conditioned incentive perspective on food cravings.

In a PET imaging study, Wang and colleagues [35] presented their participants pictures of palatable food (including the smell and taste of their preferred food) versus nonfood related pictures. These participants showed increased brain metabolism when exposed to food, especially within the insula and the orbitofrontal cortex (OFC). This proved to be important as the relatively increased metabolism within the OFC correlated significantly with self-reported desire for food. Wang and colleagues ([35] p. 1795) point out that: "This association is consistent with the known role of the OFC in processing expectation of food reward".

Pelchat et al. [36] found food craving to increase specifically BOLD responding in the insula (though not the OFC) when their participants had to imagine the sensory properties of their favorite foods. The insula is sometimes referred to as the primary gustatory cortex [37] and hence Pelchat and colleagues argued that its craving related activation reflects activation of the memory of the reinforcer.

In a more recent fMRI study, Siep et al. [38•] found increased activity in both the insula and the medial OFC when their participants were instructed to think explicitly about the delicious taste and smell of various high-calorie highly palatable food items (e.g., chocolate biscuits). Participants who were instructed to either suppress food desires or to think about the potentially adverse consequences for weight, shape and overall health when consuming a lot of snack foods, did not show as strong activity within these areas. Food craving was highest when instructed to imagine the sensory characteristics of different palatable snack foods and this again was associated with increased BOLD responding in key brain regions involving the representation of food reward.

To recapitulate, the exposure to favored palatable foods directly activates the representation of food reward that is associated with craving reactivity. The question arises whether this observed neurophysiological cue reactivity is the end result of a conditioning history. There is evidence that it is. Gottfried, O'Doherty and Dolan [39] exposed hungry participants to pairings of different picture CSs with two different desirable food odor UCSs. The participants readily learned which specific CSs predicted which odor reward. Next, the participants were fed on a meal (corresponding to one of the food odor UCSs) until they were full. Typically, the consumption of a food leads to a food specific decrease in pleasure derived from consuming that food (see, e.g., $[40,41]$ ). It momentarily decreases the incentive value of the food. In a subsequent fMRI test, presentations of the CS previously paired with this target UCS evoked less activity in the OFC and amygdala relative to the CS associated with the other non-target food UCS. Gottfried et al. conclude that a CS predicting a certain UCS is able to evoke responses in brain areas overlapping with areas activated by the UCS. Moreover, the OFC and the amygdala especially were involved in learning that the CS signals food reward. Note that the odor of a favored food is itself likely a CS associated with food reward. The picture CSs associated with food odor can thus be viewed as second order conditioned stimuli [2].

In sum, cue elicited activity, particularly within the OFC (the secondary gustatory cortex [37]), is associated with food craving and is the likely result of a Pavlovian 
learning history. Highly palatable calorie dense foods are desirable foods and exposure to its sight, smell, and taste directly reminds one of the rewarding experiences of eating these foods.

\section{Cue Elicited Craving and Sensitization}

Craving is a central concept in understanding substance dependence, or drug addiction. In their incentive sensitization model of addiction, Robinson and Berridge [42] stated that craving (or rather drug 'wanting') is the result of neural sensitization of the dopaminergic pathways in reward related structures such as the nucleus accumbens and the ventral tegmental area. This sensitization as the result of repeated drug use increases sensitivity to the rewarding effects of the given drug. Through Pavlovian conditioning, this neural sensitization allows for the attribution of excessive incentive salience to drug related cues. These cues then become highly desirable and are capable of eliciting strong craving. Note that this considerably overlaps with the conditioned incentive model for food craving as outlined above.

Wyvell and Berridge [43] demonstrated in rats that with repeated microinjections of amphetamines in the nucleus accumbens (inducing neural sensitization) these rats worked harder for a sucrose reward when being presented with Pavlovian cues associated with sucrose. Neural sensitization as the result of repeated drug administration may thus induce incentive sensitization to specific food cues (i.e., cues signalling food reward) as well. This suggests that food craving might be the result of underlying sensitization of dopamine circuitry in brain reward areas. In line with this finding, David Mela [44] suggested that caloric overconsumption contributing to obesity is perhaps the result of such incentive sensitization creating strong 'wanting' for particularly palatable high calorie foods.

When assuming that food craving reactivity is the result of incentive sensitization contributing to overeating and hence weight gain and obesity, one would expect to observe neural sensitization of dopamine reward circuitry in obese individuals. No such sensitization has been found though. In fact, obese individuals appear to have a relatively decreased dopamine D2-receptor availability [45, 46]. It appears that this low dopamine D2-receptor availability is congenital rather than reflecting downregulation caused by chronic overconsumption of palatable high calorie foods. Indeed, Stice, Spoor, Bohon, and Small [47] found that individuals with reduced dopamine D2-receptor availability due to a polymorphism in the DRD2 gene (i.e., an A1 allele of the TaqIA SNP, the TaqIA A1 genotype) are at greater risk for weight gain. They also showed in these individuals a blunted striatal BOLD response when instructed to imagine eating a palatable food. Possibly, certain people are more sensitive to their preferences for potent rewards (be it drugs, alcohol, or sugar) as it is the sole form of stimulation that still provides some degree of pleasure.

\section{Conclusion}

Pavlovian conditioning undoubtedly plays an important role in the etiology of food craving. It is argued here that learning to recognize the foods associated with a rewarding consequence increases the incentive value of these foods. This is an important notion as it means that one cannot crave palatable high calorie foods one is unfamiliar with. The development of craving reactivity requires experiencing and learning the rewarding consequences of ingesting a specific food. These rewarding consequences can be a highly palatable taste (e.g., a sweet taste) and/or energy repletion (due to a high energy density) [48].

In as much as food cravings contribute to overeating and weight gain, one way to aid weight management programs would be to repeatedly expose the individual to his favorite foods without the possibility to eat the food, a procedure termed cue exposure with response prevention. This would induce craving, but as the food cues are not reinforced by the rewarding consequences of ingestion, cue reactivity should eventually dissipate much like the extinction of a conditioned salivary reflex in Pavlov's subjects with repeated unreinforced presentations of the CS $[9 \bullet, 49]$. This should make it much easier to obtain and maintain weight loss. Indeed, Jansen et al. [50•] found reduced cue reactivity in formerly obese successful dieters. It is important to note that extinguishing cravings (food or drug craving) through cue exposure with response prevention is by no means an easy task. Conditioned flavor preferences are notoriously resistant to extinction treatment [51] and extinguished craving tends to recover outside the extinction treatment context [52].

Cue exposure with response prevention has tantalizing potential. Craving is an aversive state if one cannot satisfy it. What is important is that it is transient, as the craving for a food will eventually wane if one manages not to give in to it. Cue elicited craving or urges to eat are like a wave that grows bigger as it reaches the shoreline. The essential condition is to learn to ride that wave, to "surf the urge" as Bowen and Marlatt [53] have put it. Cue exposure with response prevention may be very beneficial in teaching someone to "wait out" the craving [54]. Whether this is true requires empirical validation.

Of course, in terms of preventing individuals from having to face intense food craving it would be best to limit the number of food cues one is typically exposed to. A lot of modern day exposure to palatable food cues can be ascribed to food marketing. Foods - especially high calorie snack foods - are advertised on websites, on television, in radio 
ads, in magazines, on billboards, in supermarkets, on vending machines, and elsewhere. Food marketing is ubiquitous and hence forms a potent cue almost continually triggering a desire to eat. For example, Harris, Bargh and Brownell [55] found that both children and adults ate markedly more food when exposed to television food advertising. Central regulation and policies are needed to allow the food industry to collectively reduce its aggressive marketing of high calorie foods [56], and in doing so limit the extent to which consumers are driven to overeat via conditioned cravings.

Conflict of Interest Remco C. Havermans has no potential conflict of interest.

\section{References}

Papers of particular interest, published recently, have been highlighted as:

- Of importance

1. Pavlov I. Nobel Lecture: Physiology of digestion. http://www. nobelprize.org/nobel_prizes/medicine/laureates/1904/pavlovlecture.html.

2. Pavlov IP. Conditioned reflexes. Oxford: Oxford University Press; 1927.

3. Woods SC. The eating paradox: how we tolerate food. Psychol Rev. 1991;98:488-505.

4. Jansen A. A learning model of binge eating: cue reactivity and cue exposure. Behav Res Ther. 1998;36:257-72.

5. Nederkoorn C, Smulders F, Jansen A. Cephalic phase responses, craving, and food intake in normal subjects. Appetite. 2000;35:45-55.

6. Weingarten HP. Conditioned cues elicit feeding in sated rats: a role for learning in meal initiation. Science. 1983;220:431-3.

7. Nederkoorn C, Jansen A. Cue reactivity and regulation of food intake. Eating Behav. 2002;3:61-72.

8. Drummond DC. What does cue reactivity have to offer clinical research? Addiction. 2000;95(S2):129-44.

9. - Jansen A, Havermans RC, Nederkoorn C. Cued overeating. In: Preedy VR, Watson RR, Martin CR, editors. Handbook of behavior, food, and nutrition. New York: Springer; 2011. p. 1431-43. This chapter describes food cue reactivity and how it is thought to be related to craving and binge eating.

10. Nederkoorn C, Smulders F, Havermans R, et al. Exposure to binge food in bulimia nervosa: finger pulse amplitude as a potential measure of urge to eat and predictor of food intake. Appetite. 2004;42:125-30.

11. Weingarten HP, Elston D. Food cravings in a college population. Appetite. 1991;32:167-75.

12. Cornell CE, Rodin J, Weingarten H. Stimulus-induced eating when satiated. Physiol Behav. 1989;45:695-704.

13. Frankort A, Roefs A, Siep N, et al. Reward activity in satiated overweight women is decreased during unbiased viewing but increased when imagining taste: an event-related fMRI study. Int J Obes. 2012;36:627-37.

14. Schaal B, Marlier L, Soussignan R. Human foetuses learn odours from their pregnant mother's diet. Chem Senses. 2000;25:729-37.
15. Havermans RC, Jansen A. Acquired tastes: establishing food (dis-) likes by flavour-flavour learning. In: Preedy VR, Watson RR, Martin CR, editors. Handbook of behavior, food, and nutrition. New York: Springer; 2011. p. 73-84.

16. Holman EW. Immediate and delayed reinforcers for flavor preferences in rats. Learn Mot. 1975;6:91-100.

17. Bolles RC, Hayward L. Crandall, C: conditioned taste preferences based on caloric density. J Exp Psychol: Anim Behav Process. 1981;7:59-69.

18. Fedorchak PM. The nature and strength of caloric conditioning. In: Bouton ME, Fanselow M, editors. Learning, motivation and cognition: the functional behaviorism of Robert C. Bolles. Washington, DC: American Psychological Association; 1997. p. 255-69.

19. Sclafani A. Oral and postoral determinants of food reward. Physiol Behav. 2004;81:773-9.

20. Zellner DA, Rozin P, Aron M, et al. Conditioned enhancement of human's liking for flavors by pairing with sweetness. Learn Mot. 1983;14:338-50.

21. Havermans RC, Jansen A. Increasing children's liking of vegetables through flavour-flavour learning. Appetite. 2007;48:259-62.

22. Johnston C, Palcic JL, Tyler C, et al. Increasing vegetable intake in Mexican-American youth: a randomized controlled trial. J Am Diet Assoc. 2011;111:716-20.

23. Birch LL, McPhee L, Steinberg L, et al. Conditioned flavour preferences in young children. Physiol Behav. 1990;47:501-5.

24. Jansen A, Tenney N. Seeing mum drinking a 'light' product: is social learning a stronger determinant of taste preference acquisition than caloric conditioning? Eur J Clin Nutr. 2001;55:418-22.

25. Johnson S, McPhee L, Birch LL. Conditioned preferences: young children prefer flavors associated with high dietary fat. Physiol Behav. 1991;50:1245-51.

26. Kern DL, McPhee L, Fisher J, et al. The postingestive consequences of fat condition preferences for flavors associated with high dietary fat. Physiol Behav. 1993;54:71-6.

27. Yeomans MR, Leitch M, Gould NJ, et al. Differential hedonic, sensory and behavioral changes associated with flavor-nutrient and flavor-flavor learning. Physiol Behav. 2008;93:798-806.

28. Zeinstra G, Koelen M, Kok F, et al. Children's hard-wired aversion to pure vegetable tastes. A 'failed' flavour-nutrient learning study. Appetite. 2009;52:528-30.

29. Gibson EL. Learning in the development of food craving. In: Hetherington MM, editor. Food cravings and addiction. London: Leatherhead; 2001. p. 193-234.

30. Zellner DA, Edwards EM. Conditioning models of food craving. In: Hetherington MM, editor. Food cravings and addiction. London: Leatherhead; 2001. p. 171-92.

31. Siegel S et al. Classical conditioning and drug effect. In: Smart R, Glaser F, Israel Y, editors. Research advances in alcohol and drug problems. New York: Plenum; 1983. p. 207-46.

32. Nolan LJ. Shared urges? The links between drugs of abuse, eating and body weight. Curr Obes Rep. 2013. doi:10.1007/s13679-0130048-9.

33. Havermans RC, Mulkens S, Nederkoorn C, et al. The efficacy of cue exposure with response prevention in extinguishing drug and alcohol cue reactivity. Behav Interven. 2007;22:121-35.

34. Carter BL, Tiffany ST. Meta-analysis of cue reactivity in addiction research. Addiction. 1999;94:327-40.

35. Wang GJ, Volkow ND, Telang F, et al. Exposure to appetitive food stimuli markedly activates the human brain. NeuroImage. 2004;21:1790-7.

36. Pelchat ML, Johnson A, Chan R, et al. Images of desire: foodcraving activation during fMRI. NeuroImage. 2004;23:1486-93.

37. Rolls ET. Taste, olfactory, and food texture processing in the brain, and the control of food intake. Physiol Behav. 2005;85:45-56.

38. - Siep N, Roefs A, Roebroeck A, et al. Fighting food temptations: the modulating effects of short-term cognitive reappraisal, 
suppression and up-regulation on mesocorticolimbic activity related to appetitive motivation. NeuroImage. 2012;60:21320. This research paper describes results of a study that demonstrate how specifically the sensory characteristics of a palatable food trigger craving.

39. Gottfried J, O'Doherty J, Dolan RJ. Encoding predictive reward value in human amygdala and orbitofrontal cortex. Science. 2003;301:1104-7.

40. Rolls BJ, Hetherington M, Burley VJ. The specificity of satiety: the influence of foods of different macronutrient content on the development of satiety. Physiol Behav. 1988;43:145-53.

41. Havermans RC, Janssen T, Giesen JCAH, et al. Food liking, food wanting, and sensory-specific satiety. Appetite. 2009;52:222-5.

42. Robinson TE, Berridge KC. The neural basis of drug craving: an incentive sensitization theory of addiction. Brain Res Rev. 1993;18:247-91.

43. Wyvell CL, Berridge KC. Incentive sensitization by previous amphetamine exposure: increased cue triggered 'wanting' for sucrose reward. J Neurosci. 2001;21:7831-40.

44. Mela DJ. Eating for pleasure or just wanting to eat? Reconsidering sensory hedonic responses as a driver of obesity. Appetite. 2006;47:10-7.

45. Volkow ND, Wang GJ, Telang F, et al. Low dopamine striatal D2 receptors are associated with prefrontal metabolism in obese subjects: possible contributing factors. NeuroImage. 2008;42:1537-43.

46. Wang GJ, Volkow ND, Logan J, et al. Brain dopamine and obesity. Lancet. 2001;357:354-7.

47. Stice E, Spoor S, Bohon C, et al. Relation between obesity and blunted striatal response to food is moderated by Taq1A1 DRD2 gene. Science. 2008;322:449-52.
48. Havermans RC. Increasing children's liking and intake of vegetables through experiential learning. In: Watson RR, Preedy VR, editors. Bioactive foods in promoting health. Oxford: Academic; 2009. p. 273-83.

49. Frankort A, Siep N, Roefs A, et al.. The craving stops before you feel it: neural correlates of chocolate craving during cue exposure with response prevention. Cereb Cortex. 2013. doi:10.1093/cercor/ bht016.

50. - Jansen A, Stegerman S, Roefs A, et al. Decreased salivation to food cues in formerly obese successful dieters. Psychother Psychosom. 2010;79:257-8. The probability of longer term weight maintenance after weight loss is small, but the individuals who do manage to keep off the weight show reduced cue reactivity. This supports the assumption that direct efforts to reduce cue reactivity may be beneficial in treating obesity.

51. Havermans RC, Jansen A. Evaluative conditioning: a review and a model. Neth J Psychol. 2007;63:38-49.

52. Thewissen R, Snijders SJBD, Havermans RC, et al. Renewal of cue-elicited urge to smoke: implications for cue exposure treatment. Behav Res Ther. 2006;44:1441-9.

53. Bowen S, Marlatt A. Surfing the urge: brief mindfulness-based intervention for college student smokers. Psychol Addict Behav. 2009;23:666-71.

54. Rohsenow DJ, Monti PM, Rubonis AV, et al. Cue exposure with coping skills training and communication skills training for alcohol dependence: 6- and 12-month outcomes. Addiction. 2001;96:1161-74.

55. Harris JL, Bargh JA, Brownell KD. Priming effects of television food advertising on eating behavior. Health Psychol. 2009;28:404-13.

56. Schwartz MB, Ustjanauskas A. Food marketing to youth: current threats and opportunities. Childhood Obes. 2012;8:85-8. 